\title{
15 Lessons from rural Sweden and looking ahead
}

This chapter brings together the content of this book and gives an overview of the main conclusions drawn. This chapter pays special attention to issues of youth in rural areas, farm crime, and crime against environment and wildlife, as well as cases of violence against women, with particular focus on Swedish rural areas. Crosscutting issues are summarized in this chapter before new research frontiers are suggested and conclusions drawn.

\section{Lessons from the book}

\section{Part I - Introduction}

This part introduces the reader to the book's aim, scope, and structure. Chapter 2 presents arguments for why rural areas matter in a criminological perspective. The chapter attempts to unravel simplistic views of rural areas as crime-free and/or "strange" or dangerous by discussing a number of issues that reveal rural areas as both safe and criminogenic. Low crime rates, typical of rural areas, do not necessarily mean safety for all when victimization is unequally distributed, perhaps concentrated in a specific group. This part concludes with a review of the theoretical framework adopted in the research on which the book is based and reflections on the process of doing research, including issues related to the data.

\section{Part II - Trends and patterns of crime}

Chapter 4 compares crime rates and prevalence in Sweden with those in the United States and the United Kingdom. In all three countries, urban crime rates are higher than rural ones, regardless of definitions of crime types and how rural areas are conceptualized. The comparison of the international data shows mixed but often declining trends for rural areas but especially for urban areas. The hypothesis that urban and rural crime rates in the United States and Sweden are converging is also discussed. Then, the analysis focuses on specific types of violent and property crimes in rural areas, drawing conclusions for rural areas in multiple countries whenever possible. Inequality of victimization by groups is 
still a major challenge when crime trends for different areas are compared. Most groups that are overrepresented in repeat victimization are found in urban areas, but for certain crimes and for frequent victimization the differences between those living in urban and rural areas are small or nonexistent. As is discussed in this chapter, the analysis of inequality of victimization demands an approach that is informed by crime, group, area, and time.

Chapter 5 takes the first step toward a more nuanced picture of crime in rural areas by modeling the geography of property and violent crimes in rural Sweden. Results from the regression models indicate that accessible rural municipalities were more criminogenic in the late 2000s than they were in the 1990s, particularly municipalities located in southern Sweden. Crime rates are higher where urban criminogenic conditions emerge, not necessarily in urban areas but in settings that have strong links with urban centers. These results show increasing dependencies between the city and the countryside, not only with regard to the population's demographic and socioeconomic characteristics but also lifestyle and criminogenic conditions. Changes in routine activities associated with existing and new risk factors are indicated as potential causes of the increased vulnerability of accessible rural areas in recent decades. Moreover, some evidence of anomic conditions is found when a population increase in municipalities affects crime rates. Yet, it is still unclear whether pro-social institutions moderate or mediate the impact of economic conditions on the crime rate. Chapter 5 finishes with reflections on why new theoretical frameworks are needed to help interpret a multinational comparison of rural-urban dependencies, some of which are evident through changes in rural residents' consumption, lifestyles, and victimization.

\section{Part III - Perceived safety in rural areas}

Chapter 6 attempts to illustrate that the safety perceived by people living in rural areas is a more complex phenomenon than overall expressions of fear of crime suggest. The implication of this is that there is no single remedy for the problems of crime and perceived safety, let alone a single actor (such as the police) that can tackle such problems. The book argues that perceived safety is a collective project that requires constant assessment by those who produce it: those who are in fear, the community itself, and other stakeholders. Perceived safety is both the cause and the product of people's everyday life practices and experiences, embedded in a context that is not politically neutral, or limited to the village, rural areas, or individual nations. Undoubtedly some tangible attributes of perceived safety stem from local conditions, where daily anxieties arise from victimization, discrimination, economic change, and other root causes of fear.

Instead of reducing the issue of perceived safety to the risk of victimization, Chapter 7 looks beyond actual statistics on perceived safety between rural and urban areas to shed light on the nature of fear among people living in rural areas, with particular attention to rural areas in Sweden. Several groups of individuals declare themselves to be more fearful than others. This group may be composed 
of those who are more vulnerable to crime in the first place, for a number of reasons, and therefore more fearful, reflecting concerns about crime, stability, and social change. Since 2006, certain measures of perceived safety have decreased among the poor in Sweden. For them, poor perceived safety affects their mobility patterns and quality of life. Inequality in victimization may also explain the pattern. The poor are victims of crime more often and reveal more anxieties than wealthier groups in Sweden. However, as elsewhere in the international literature, fear of victimization in Sweden does not reflect the severity of the crime. Rather, fear of crime appears to reflect reductions in perceived crime risk, that is, changes in the situational conditions for crime, especially for car-related crime. A more nuanced picture of perceived safety in rural areas is presented in chapters 8-10. In these chapters, victimization and fear are discussed in relation to, for instance, young people and women.

Several lessons may be learned from these patterns of perceived safety in Sweden. One lesson is that urban-rural divides in perceived safety (with more people being fearful in urban environments than in rural) represent a rough picture of reality, because there is inequality in both victimization and perceived safety by groups. This is exemplified in Part IV of this book. Chapter 7 concludes by questioning the role of police and policing in reducing fear of crime and boosting perceived safety in rural areas.

\section{Part IV-Crime in a rural context}

Chapter 8 focuses on farm crime and environmental and wildlife crime and to a lesser extent, it touches on rural production of narcotics. The chapter has two sections, and both place Sweden in an international context. Farmers are victimized mostly by theft of diesel and other fuels, machinery, and tools as well as by different types of fraud. As many as three out of 10 farmers or their properties declared to be a victim of crime in 2012-2013. Farmers in the south have been exposed to crime two or more times more than the national average, but there are differences by type of crime; for example, theft of fuel is slightly higher in northern Sweden than in the south. Underreporting is a problem with these offenses. Findings also show that despite community efforts to deal with farm crime, victimization has not decreased.

This chapter also provides a glimpse of environment and wildlife crime (EWC) in Sweden. Police records and newspaper articles indicate an increase in EWC in the past decade. It is important to note that before 2007 only crimes with a suspect were recorded by the police, which partly explains the rise between 2006 and 2007. Although crimes against the environment and wildlife are rural phenomena, the geography of EWC varies by crime type. The proportion of serious EWC, unlawful use of chemicals, and crimes related to nature and wildlife is similar in both urban and accessible rural municipalities. Urban and accessible rural municipalities also show high numbers of minor EWC reported, such as littering, garbage dumping, and illegal waste transportation. Remote rural municipalities have a significantly higher percentage of chemical 
environmental crimes, comprising unlawful handling of chemicals, disruption of control, and disregard of regulations and permits for the use of chemical compounds. For crimes against the protection of nature and wildlife (animal abuse and illegal animal possession as well as disregard of protected species), a slightly higher percentage is recorded in remote rural municipalities than in accessible and urban municipalities.

Drug production attracts less attention than farm crime does in Sweden, compared with the United States or Australia. According to police records, drug production in Sweden tends to be concentrated in rural areas. Media articles report cases of cannabis cultivation in apartments and cellars but also on farms in southern Sweden. Production of synthetic cannabis has also been reported in northern Sweden. However, it is unclear how these reports relate to levels of drug addiction, and much less is known about the nature of users and potential dealers in the rural context. Little is also known about the potential links between drug producers/dealers in rural Sweden and international drug providers through, for instance, the internet.

Chapter 9 turns to a more familiar issue: the paradox of young people, seen either as the "saviors of the countryside" or "the agents of local trouble." This chapter attempts to illustrate both sides of the coin using available official statistics. First, demographic, socioeconomic, and lifestyle differences among young individuals in Sweden are introduced as a background for understanding regional differences in offending and victimization among youth. This is followed by a discussion of factors associated with youth crime and victimization in rural areas; apparently they are similar to those in urban areas. As much as possible, the Swedish case is compared with the international literature, often with examples from British and North American research.

The chapter closes with a discussion of two superficially divergent issues: motorcycle groups that have confirmed links to numerous criminal activities, and young women who come to Sweden after being recruited in remote areas in neighboring Baltic countries. The impact of the motorcycle groups and their networks of influence in rural areas is controversial, as younger members may belong to the community, and therefore their actions are somewhat tolerated by locals. For a certain group of women, the chapter traces individuals' journeys from regions in the Baltic countries to urban Sweden, illustrating the rural-urban link. Young people often become cross-border commodities, forced to engage in activities orchestrated by groups that look like criminal networks. Police statistics of these cases are inexistent or incomplete. Evidence used here is based on interviews (with young people brought to the country, mostly to big cities) and other data sources gathered by supporting organizations.

Chapter 10 points out the barriers women living in rural areas face when reporting violence, particularly when the perpetrator is known to the victim. Following a brief discussion of international urban-rural trends in rates of violence against women, the basis for an analysis of the Swedish case is provided, a list of individual and structural factors pointed out in the international literature as determinants of violence against women in rural areas. In Sweden and 
elsewhere, reporting rates for violence against women vary geographically for different reasons, which makes it difficult to disentangle "shadow figures" of violence against women between urban and rural areas. Statistics reveal more violence against women in urban municipalities in Sweden, and yet in rural areas more cases of violence against women are being recorded by the police, which is also confirmed by health statistics (hospitalization rates). The increase may reflect a genuine change in the level of criminal activity but could also result from a combination of other factors, such as a rise in victims' willingness to report to the police and other authorities, society's increased sensitivity to violence, improvements in criminal justice practices, and equally important, changes in the law. It is unclear why indicators of gender equality do not capture the dynamics of the geography of violence against women, either in rural or in urban municipalities. One reason may be the fact that police statistics reflect society's (in)capacity to deal with the problem and the communities' tolerance for violence as part of their daily life, embedded in different gender contracts. The international literature indicates that violence has a greater impact on women living in remote areas than on those living in urban centers. In the case of Sweden, no systematic evidence has been found on this point. At the same time, being a "welfare state" with a long tradition of a women's movement does not guarantee a homogeneous support network for women suffering violence in the domestic realm.

\section{Part $V$ - Policing and crime prevention in a rural context}

Part V is divided into four chapters: Chapter 11 discusses issues of rural policing, Chapter 12 is devoted to youth-related problems, Chapter 13 focuses on environmental and wildlife crime (EWC), and Chapter 14 builds on Chapter 10 by discussing crime prevention against violence against women, with the focus on rural areas.

One reason Chapter 11 is devoted to rural policing is the difference in police work and organization. International literature long highlighted the distinctiveness of rural policing, with its isolating and lonesome nature, and the dependence on one's neighbors and community within which the police lived. Rural crime issues are different nowadays from those decades ago, and certainly rurality is a complex mix that imposes new demands on policing that go beyond issues of remoteness and isolation. Policing is no longer a job for the public police force only. A good sign is that nowadays there are about 300 community partnerships (crime prevention groups) around the country. They are often composed of a core of representatives from the municipality, police, and schools. This homogeneous format for crime prevention was inherited from the traditional decentralized municipal planning system in Sweden but, more importantly, from the structural changes imposed by police reform around local crime prevention in the mid-1990s. The economic downturn in the 1990s affected public resources and most likely the full implementation of community policing schemes. Top-down national crime prevention policies focusing on big-city 
problems neglect the special demands of sparsely populated or remote rural areas. For instance, property crimes targeting enterprises, farm crime, and environmental and wildlife crime often fall outside a crime prevention group's agenda. Police-recorded crime does not allow typical rural crimes (e.g., farm crimes) to be registered. Members of crime prevention groups who were interviewed unanimously designated youth issues as the most important for crime prevention councils in rural areas. Most of the work by such groups does not include any strict follow-up. When it does, the evaluation is characterized by simple assessment procedures. Different types of crime prevention models are usually "imported" from other municipalities as examples of good practices. Little thought is put into the adequacy of these remedies in a particular rural context. This weak attachment to local needs imposes further challenges to crime prevention after the new police organization come into force in 2015. With the new police authority more consistency and uniformity of routine police work is expected, as the existing 21 police authorities disappear. The centralization of certain functions should make police work more effective and economically viable. The 2015 police model also relies on intentions to maintain strong links with local policing. Future work is expected to build on experiences with existing local partnerships between the police, municipal authorities, the private sector, and citizens that stem from experiences from community policing reform from the 1990s on.

Chapter 12 takes the issues of Chapter 8 forward by discussing the main crime prevention initiatives related to farm crime and EWC. The role of the community in dealing with farm crime and EWC in rural municipalities through crime prevention initiatives is given special attention. Farm crime and EWC are not a top priority on crime prevention (CP) councils' agendas or by the rural police. Exceptions are municipalities that are targeted by these problems, where environmental inspectors and the police play an important role in crime detection. Although local CP councils demonstrate good knowledge of what to do when a farm crime or EWC occurs in their municipality, there is an overall lack of knowledge among those interviewed from CP councils about what works and what does not work when tackling farm crime and EWC. Because they are rare (or not easily detected), such crimes normally are not followed up and are considered one-off events detected by environmental inspectors and police. Public (including CP groups) and private partnerships appear to be flourishing in municipalities that are often targeted by farm crime and EWC. The chapter reviews new forms of surveillance and protest against farm crime and EWC using ICT and social media, then discusses in detail an interesting case of protest against EWC. An example is the protests about iron ore mining in Kallak, Jokkmokk, in northern Sweden.

Chapter 13 turns to crime prevention activities aimed at youth in rural settings. The role of community in dealing with the problem in rural municipalities is given special attention. Findings show that crime prevention groups in rural areas appear to be well prepared to deal with daily youth problems, or at least they have the organization to deal with individuals who run a higher risk of 
offending or to prevent other children and teenagers from engaging in risky behavior. Keeping youngsters entertained during their free time is often suggested as a long-term action to prevent youth problems. Most crime prevention aimed at young people revolves around recreational centers and activities. However, it is unclear how much social control driven by crime prevention initiatives affects young people's quality of life. In many rural communities, where "parent-free space" is limited, emphasizing the need for parents to police their offspring may not be well received by young people, including those who would never consider getting involved in trouble in the first place. Spaces for young people may be jeopardized by extending police powers to safety walkers and parents that suddenly feel they own the spaces being regulated and controlled. In the long run, well intentioned crime prevention actions could be perceived by youth as coercive, potentially influencing young people to move away and seek anonymity. Whatever approaches are taken by crime prevention groups, interventions are bound to have consequences for the groups that they are aimed at - in this case, young people. Another problem is that little knowledge exists about what works when dealing with youth-related problems. When they are assessed, they do not always contain the proper information to help other practitioners replicate the projects in their own contexts.

Chapter 14 illustrates challenges in preventing women abuse in rural communities. It starts by discussing current activities that address violence against women in Sweden, following the diagnosis of violence against women presented in Chapter 10. Secondary data, email surveys, media excerpts, and face-to-face interviews capture examples of current prevention initiatives against women's violence in rural settings. Underreporting of this offense is the result not only of the victim's silence but also of the tolerance and inhibition of the social circles surrounding the victims and responsible organizations - perhaps starting with the subtle role local crime prevention councils play in dealing with this particular type of violence. If rural crime prevention deals with women's safety, it often focuses on perceived safety in outdoor environments. It seems that, so far, interventions against aggression toward women have often been guided by the dichotomy of private versus public spaces that also guides the efforts of local crime prevention councils and, to some extent, the police.

Violence against women is regarded as important by all interviewed individuals working on local crime prevention councils. However, they believe that social services, other members of municipal social boards, or health experts are the key actors to deal with domestic violence at the local level. They also emphasize the importance of women's shelter organizations (which are rarely found in remote rural areas) and, most importantly, that domestic violence is an issue that requires the coordinated actions of local actors. Women's shelter organizations are a cornerstone of efforts assisting victims of violence in Sweden. Yet, they are concentrated in urban areas. One-third are in accessible rural municipalities, and only three in remote rural municipalities in Sweden. Crime prevention has long been based on principles of behavior avoidance, demanding from women the difficult decision to leave their homes to stop 
violence. Interventions aimed at potential perpetrators (men at risk), as the example from Gotland shows, can help prevent violence in a more pro-active way. The view is that all victims of domestic violence, regardless of gender or age, have the right to assistance and protection.

\section{Future research questions}

Several themes emerged throughout the book. Some of these are highlighted here, as they represent remaining research questions in the field and provide new direction for future research.

Although crime in rural areas may not always be specifically rural, its nature fails to be fully understood by the current urban-based theories. A key issue for future research is to understand the causes of changes in crime rates in rural areas and how they relate to specific rural conditions for each area. Crime trends have to be considered against a background of what is happening in these areas: changes in their economic base, each population's socioeconomic and demographic challenges, and people's routine activities - just to name a few issues. Such conditions affect levels and processes of social control in these areas and, consequently, crime.

Following Donnermeyer and DeKeseredy's (2013) suggestions, the role of social organization on the formation of criminogenic conditions of rural areas (as opposed to social disorganization) is a fundamental research question to be further investigated in the future. As these authors well observe, crime manifests itself in rural localities in ways that both conform to and challenge conventional theory and research, thus the next step is to empirically test some of the alternative approaches to crime in rural areas.

Another important area of future research is the concept of population at risk, using both resident population and floating population (by vehicle traffic or alternative sources such as opportunistic sensors in mobile phones), as affected by high and low seasons (e.g., summer vs. winter). The book highlights the need for more nuanced evaluations of whether crime affects rural municipalities, as much of the debate on the impact of temporary population on local communities is often based on perceptions of increased crime during high seasons.

In terms of the geography of crime, upcoming studies should attempt to include indicators of social change rather than the ones used in this book. In addition they should also test the importance of differences in regions' functionality on crime levels (e.g., if they contain capital cities, holiday resorts, or industrial towns), because this affects human interaction and, as a consequence, conditions of crime. The testing of variables that serve as indicators of pro-social institutions as moderators of inequality on crime is one example.

Another important question in rural areas is whether thefts are committed by local offenders or are the actions of outsiders coming from neighboring communities. Traditionally, outsiders are often blamed for certain types of crime. Of course, this is an empirical question that can be checked looking at how the flow of information from the targets reaches potential offenders, supposedly living outside the community. It is possible that some offenders travel between 
municipalities to commit a crime, but no evidence is available for how far offenders travel in Swedish rural context. Past research on urban environments suggests, however, that the majority of criminals commit a crime close to where they live which, for most crime types, is an area smaller than municipal boundaries. Data on the location of offences, offenders and victims and/or targets is necessary to assess whether rural crime is committed by locals or by those travelling to such municipalities for the purpose of committing an offence.

This research shows some factors that affect perceived safety are associated with individual, group, and/or area characteristics. Moreover, some processes triggered by fear seem to have the same impact on people's lives regardless of whether they take place in an urban or a rural area or elsewhere. Future studies should be devoted to the nature of perceived safety in rural areas. Given the multifaceted nature of perceived safety and the complexity of fear of crime, a relevant question is, how can fear be informative to those living and working with safety issues in rural communities?

Another remaining question refers to the current and future challenges for rural policing and crime prevention in rural areas. Crime has become less dependent on space, so the fear of being a victim of crime may be fed by borderless "glocal" forces. An individual living in in a remote rural area of Sweden may run the same risk of being victimized by computer fraud as someone living in New York City. New types of computer-based communication may become facilitators for traditional crime in the physical world, such as pedophiles looking for potential victims on youth chat forums. Information technology also connects people without regard to their physical location but may leave tracks as soon as they move in (real and virtual) space. This imposes new challenges for crime prevention, because law enforcement authorities have to find online criminals that may reside far from the police authority's territorial jurisdiction. Moreover, further investigation should look at the profile of victims of fraud in rural areas, to shed light on why farmers are often vulnerable to this type of crime. Note that many Swedish rural communities have an overrepresentation of elderly, a group often targeted by telephone calls from strangers, some leading to fraud.

In relation to farm crimes, larger properties are more certain attractors than smaller ones, as they often have more locations to steal from, and if they are fairly accessible they make the right target if nobody is around, such as in remote areas and accessible rural areas. Little is known about the situational crime conditions of farm crimes. In order for a crime to occur there must be an intersection of a potential target (e.g., a tractor), a motivated offender passing by and poor guardianship - at the 'right place' (tractor is visible from the road) at the 'right time' (vacation time, no-one is around). The combination of these conditions are expected to provide the necessary situational conditions for far crime. A question remaining for future research is the assessment of how seasons regulate the flow of people, activities, and consequently crime. In addition, there is a need also to investigate the existence of a demand for drugs in rural contexts among youth that seem to be both producers and users of popular synthetic drugs. The relationship between alcohol and drug consumption should be further 
investigated in a broad social and cultural context for rural communities. There are reasons to believe that, in certain rural contexts, both alcohol and narcotic use is accepted within certain limits.

With regards to youth problems, researchers should strive for a more nuanced view of young people living in rural areas as a group. It is also important to obtain better knowledge about the nature and quality of youth recreation centers and social activities, for instance, whether or not these provisions fulfill the demands of youth groups in contemporary rural environments. Another issue is whether the provisions have any influence on individuals' predisposition to offend, particularly for those that are already at risk.

In terms of violence against women, a more accurate inventory of types of services and support for women facing violence in the domestic environment in rural areas is needed. New understanding that draws on rural women's perspectives of violence in the domestic realm is required to delineate a clear picture of women's needs, not only as victims but, more importantly, as agents of their life choices. Such needs pose a considerable challenge to academics, criminal justice authorities, and policy makers. Also, there is a need to assess whether and how different gender contracts affect local social control and criminal justice practices toward women victims of domestic violence. This includes the treatment that women receive on a daily basis, through municipal social services, healthcare, and supporting nongovernmental organizations, such as shelters.

Safety is often linked to the image of rural idyll, a refuge from urban life. The literature on the attractiveness of rural areas points out the importance of safety as an asset that attracts not only tourists but also new residents and businesses. An interesting research question would be the one that connects safety to rural development and social sustainability of rural communities. Is safety a component of rural attractiveness? And how does it take root in different types of rural areas?

As with the research in this book, any future research must deal with data accessibility and quality. Current research is limited by what official statistics can offer to cover the types of crimes that are relevant for rural areas. Another problem is underreporting of certain types of offenses. Current sampling used in crime victim surveys does not allow breakdowns of groups of interest within rural areas, which is a limiting factor for rural criminology. These data-related problems limit the advances that can be made in research and, more importantly, affect the scope of crime prevention and safety interventions.

\section{Concluding remarks}

The main goal of this book is to contribute to the knowledge base on crime, perceived safety, and crime prevention in rural areas, putting Sweden in an international perspective. These issues are often neglected in both criminology and rural studies. Rural areas' relatively low crime rates have been thought to be the main reason for the neglect of the topic. Another reason is that patterns of crime are believed to be homogeneous across rural areas, because "rural" is everything that is not urban, which is another misconception. This book attempts to 
challenge the rural-urban dichotomy that far too often leads to a disregard for the impact of different rural contexts on crime and safety and neglects the dynamics of rural areas as arenas composed of active agents.

Several principal themes recur throughout this book. They can be summarized as follows. Crime does not happen in a vacuum. Crime is the result of historical, political, demographic, socioeconomic, and cultural processes that characterize a specific place at a specific time. The implication of this is that safety in rural environments depends on context, so it should be analyzed using caution. In each country, or in each framework (e.g., legal, political, historical), the underlying factors that trigger crime may be different. Crime per se may be just the "tip of an iceberg" of different social problems. One can hardly claim that there is something in particular about rural areas to explain why an individual commits a crime, yet, there are reasons to assume that there are features of rural areas that differently affect the situational conditions of crime. For instance, geographical isolation is part of the dynamic of crime in rural areas.

Another recurring theme is that safety in rural areas is a multi-scale process. More than ever before, rural areas are exposed to external influences - some global - that directly affect localities. In the past, media played the key role in shaping stereotypes of rural safety, as my UK experience showed me. However, the process going on now is not quite the same. The new social order affects the way the productive system shapes the supply of jobs (e.g., laborers coming from abroad) and makes patterns of consumption independent of geography, for instance, through the widespread use of ICT. As most crimes depend on human interaction, crime takes new shapes, victims, and places - some virtual. This means that even in rural areas, safety may not follow homogeneous trends or patterns. Unequal victimization makes certain groups and places more vulnerable than others at certain times. Any attempt to generalize about "what rural safety may be" runs the risk of neglecting whose safety is in focus. This leads to the next recurring theme in this book.

Perceived safety has a reflexivity component, which means that its nature depends on those who produce it. Reflexivity takes place when the observations or actions of individuals in the social system affect the very situations they are experiencing (Loader \& Walker, 2007). Thus, although security services are becoming tradable commodities in today's market economies (e.g., commodification of police services by security companies), they are still seen (and demanded) by individuals as basic components in a collectively defined social contract, that is, as a public good. Security provision is also an arena for the involvement of civil society, a development that is positive (BRA, 2009; Yarwood, 2011, 2014). Overall this development has unintentionally created a gray zone of action between actors, in which assigned tasks are no longer obvious from the point of view of the observer (e.g., a rural resident). This uncertainty of "who does what" in security provision may be triggering anomic feelings and legitimizing criminal actions.

The international evidence on crime prevention in rural areas is limited. Local crime prevention groups are, as far as the Swedish case is concerned, composed 
of a hard core of representatives from the police, the municipality, and schools. This "institutionalized" model is partially inherited from the traditional decentralized municipal planning system in Sweden but also a result of, among other things, structural changes in the police (and policing) since the mid-1990s. Moreover, crime prevention guidelines and practices overlook the nature of rural crime, its seasonality, and what happens outside the urban core of rural municipalities. Evidence from rural Sweden shows that local crime prevention groups face a number of challenges (e.g., appropriate skills, resources) but show indications of being well prepared to address youth-related problems more than any other crime- and safety-related problems. Yet, their practices are guided by routines that do not give priority to rigorous evaluation of interventions.

This book analyzes crime, perceived safety, and practices in crime prevention in rural areas using a toolbox of quantitative and qualitative methods within a Crime Science framework, here presented separately in each chapter. It is important for researchers to select methods of analysis that are appropriate to the goals of each research project, related, of course, to the theoretical framework guiding that particular analysis. The analytical challenges posed by currently available data and previously applied methods should be further investigated.

Finally, the findings here raise questions of whether there is a need for criminological theories (or new theoretical frameworks) that can grasp large-scale crime patterns. As it is now, most environmental criminology theories fit the analysis of intra-urban underlying forces of crime, at best, but do a poor job identifying criminogenic conditions that extend over large geographical areas. This is particularly true for areas that are sparsely populated, rural, and cover large extensions of the country, and where human interactions happen in nodes in space. Is there a need for theories, methods, and data that can better fit the rural context? In essence, Crime Science allows the distillation of knowledge from a large array of divergent disciplines into a coordinated response to crime. How can Crime Science contribute to both theoretical and empirical development in rural criminology? This book is an attempt to start to answer that question.

\section{References}

Brottsförebyggande rådet - BR (National Council of Crime Prevention). (2009). Samverkan i lokalt brottsförebyggande arbete. Stockholm: Rikspolisstyrelsen, Sveriges kommuner och landsting.

Donnermeyer, D., \& DeKeseredy, W. S. (2013). Rural criminology. Abingdon: Routledge.

Loader, I., \& Walker, N. (2007). Civilizing security. Cambridge: Cambridge University Press.

Yarwood, R. (2011). Whose blue line is it anyway? Community policing and partnership working in rural places. In R. Mawby \& R. Yarwood (Eds.), Rural policing and policing the rural: A constable countryside? (pp. 93-105). Farnham: Ashgate.

Yarwood, R. (2014). Lost and found: The hybrid networks of rural policing, missing people and dogs. Journal of Rural Studies, 39, doi:10.1016/j.jrurstud.2014.11.005. 